\title{
10
}

\section{PRIA educates the community}

\author{
Mandakini Pant
}

\section{A. Women Political Empowerment and Leadership (WPEL)}

Gender is a salient factor in participation and representation in democratic decentralized governance. The Constitutional Amendment Acts (CAAs) enabled 33 per cent representation of women in panchayats and municipalities. While Article $243 \mathrm{G}$ and $243 \mathrm{~W}$ of the Constitution empowered the state legislatures to endow panchayats/municipalities with such powers and authority as may be necessary to enable them to function as institutions of self-government, the provision of reservation (Article 243D and 243T) gave an opportunity to them to hold formal positions of power and, in turn, to participate in the decision-making process. The political restructuring and affirmative action aimed to build a critical mass of women's leadership in decision making, which in turn would make a meaningful difference to the outcomes of governance.

The needs of women leaders (elected representatives) are different from elected male representatives. Women leaders are by and large first-generation leaders. Their capability building is, therefore, crucial. In keeping with the mandate of the Constitution, i.e., securing women's participation in local governance institutions, more attention must be paid to the training of women leaders. Women need to be politically enlightened not only about their rights and duties, but also about the nature of constitution, concept and relevance of local body administration and government policies and schemes.

Training should enable them to become agents of their own development. This implies that training interventions, in addition to imparting requisite functional skills, must also empower them to function in public space with determination. Institutionalized gender-based inequalities and pressures disempower them. Training interventions, besides orienting them to governance procedures and programmes and imparting requisite functional skills, should also underscore the importance of gender sensitization. A gender transformative capacity-building approach would contribute towards building gender-sensitive institutions where both women- and men-elected representatives, despite their different needs, priorities and aspirations, contribute to development processes.

Training for building capacities of women leaders has a deficit perspective. Elected representatives lack the skills to govern; they need training. The underlying 
assumption is that once people acquire the skills, they will automatically use those skills. The training interventions with mere emphasis on orientation to procedures and programmes and imparting requisite functional skills are unlikely to qualitatively change the participation of women leaders. The gender component in training is missing. The emphasis has mostly been on giving training in technicalities of governance. Training has not addressed issues of unequal gendered power relations that generally constrain women's political participation. Training focuses on professional development, emphasizing skill development, but avoids behaviour, attitudes and personal empowerment issues. The change agents are actually not motivated to change the status quo (Farrell and Pant, 2009).

\section{The programme}

PRIA initiated a project in 2008 on WPEL to address the gaps in the education and training of women leaders for political roles in institutions of local selfgovernance, at both urban and rural levels. It was premised on following three fundamental principles: (a) equality between women and men; (b) the right to full development of potentials; and (c) the right to self-representation and selfdetermination. The project assumed that women leaders are an effective interface for poor women to constructively deal with the panchayats and municipalities. They can provide a basis for collective action on gender needs in panchayats and municipalities and lobby for inclusion of women's interests in local bodies. While WERs (women elected representatives) share a political mandate of leadership as people's representatives, non-WERs from informal associations, self-help groups (SHGs) and community-based organizations (CBOs) assume de facto leadership roles. The poor women in villages and urban slums find them more articulate, and trust they would speak on their behalf in the meetings at public forums. Women leaders from both categories, when organized, can contribute to greater agency of women in articulating and claiming rights. Organized as a women's network, they can provide a basis for collective action around both community and gender issues, and provide a basis for a wider level of advocacy and lobbying in defence of women's interests, in local bodies.

Political empowerment was seen as providing women leaders with the capabilities to articulate their needs and priorities clearly as well as to negotiate from a position of strength, and participate effectively in the working of panchayats and municipalities (ibid.).

Women leaders in the WPEL project included current WERs, ex-WERs, non-WERs, who could be citizen leaders; members of CBOs such as women collectives, self-help groups (SHGs), etc. The project was implemented in Jehanabad district in the state of Bihar; Mahendragarh, Sonipat, Fatehabad and Sirsa districts in Haryana; Jaipur and Jhunjhunu districts in Rajasthan; and Ahmedabad and Sabarkantha districts in Gujarat. Women leaders in these states are severely constrained by the lack of access to critical resources such as information, education, skills, along with the denial of opportunities and choices, due to gendered roles and responsibilities. 
The criteria for the identification of potential women leaders from elected representatives and women collectives (SHGs) and citizen leaders were set as below:

- proactiveness in taking up community issues;

- working with community groups/larger political groups;

- willingness to contest elections;

- ability to articulate.

- Training and education for political empowerment and leadership was a three-step process.

- Local-level half- or one-day workshops in districts for initial orientation on the roles and responsibilities of women leaders in the governance and identification and selection of women leaders for advanced levels of education for political empowerment at the state level.

- Three days' state-level residential workshop for potential leaders identified at the local-level one-day workshop. The state-level workshop aimed to provide capacity-building initiatives on the issues identified through a training needs assessment. The workshop also aimed to identify and select leaders for further advanced levels of education for political empowerment of women leaders at the national level.

- Five days' national-level workshop (National School) for political empowerment.

It was envisaged that a core group of potential leaders of approximately 100 would emerge from this school.

Education and training for political leadership had multipronged objectives were:

General

- to enhance leadership skills and self-confidence levels;

- to provide women leaders a platform to share experiences;

- to enable them to voice their concerns and contest as elected leaders.

Specific

- to build perspectives;

- to mobilize women leaders to network on a common issue, interest or concern, and articulating their common concerns and priorities in meetings to influence district level planning and implementation;

- to demystify the social construction of gender to initiate the processes of change by enabling women leaders to make informed choices and exercise power;

- to build agency of women leaders.

\section{Content}

- Perspective building on governance, gender and leadership and their interrelationships, gender, gender discrimination, sexual harassment; violence against women, sanitation. 
- Knowledge building on the Constitution of India, decentralized governance, state provisions.

- Skill building in networking, interfacing, communication - public speaking, campaigning and advocacy, computer training, constituency building, team building.

- Agency building to participate and articulate their concerns and priorities.

\section{Training methodology}

The facilitators were well rooted in the issues relating to women leadership. By skilfully using participatory learning methods, they facilitated the learner group to understand their roles as leaders. Training methodology was a mix of participatory learning and action methods as follows:

- lectures;

- PowerPoint presentations;

- games;

- group discussions;

- case study analyses;

- films;

- interface with media, government officials, Chief Minister of Delhi, Ms. Sheila Dixit.

\section{B. Strengthening Scheduled Caste leadership in Panchayati Raj institutions (PRIs)}

The 73rd Constitutional Amendment Act (CAA) in 1992 provided a constitutional mandate to panchayats. The act particularly sought to correct the prolonged marginalization of poor, marginalized and under-represented people such as women, Scheduled Tribes (STs) and Scheduled Castes (SCs). The mandatory provisions of: (a) reservation of seats; and (b) the obligatory gram sabha meetings gave SCs in villages an opportunity to participate in political decision making.

SCs are now occupying leadership positions in local bodies. However, their leadership has yet to achieve significantly social acceptance, as envisaged in the spirit of the Constitution. The studies on SC leadership have revealed that SCs, as elected representatives, have not been not able to articulate group-specific interests or to exercise their own judgements in decision making. They did not take part in deliberations or contribute to major decisions. A number of SC representatives were stoically dependent on the elite of the village and remained answerable to the elite. Being undereducated and inexperienced, they were often not allowed to carry out their mandate. Their efficacy was always under scrutiny; their views were not considered significant and they were not included in meetings (Tandon, 2008).

Caste-based identities and practices still continue to exclude them from exercising leadership roles. Socio-economic vulnerabilities limit their capacities to articulate and to act upon their claims and concerns. The gap between the 
formal recognition of the right to participate and its actualization still remains large even after fifteen years of constitutional mandate.

\section{The programme}

The programme Strengthening Scheduled Caste Leadership in Panchayati Raj Institutions (PRIs) aims to strengthen SC leadership by providing them opportunities for systematic learning; facilitating such learning; and supporting capacity enhancement on an ongoing basis. The proposed programme envisaged that SC leaders would strategically use information and knowledge, act upon their concerns, organize and make demands upon panchayats (assemblies at local level) to change and/or influence policies and practices that affect their lives.

Education and training for political leadership had multipronged objectives as below.

\section{General}

- to motivate the communities for active participation in PRIs;

- to build capacities to express clearly one's viewpoint;

- to strengthen reservations of SCs in Panchayati Raj by making them aware of their potential and power.

\section{Specific}

- perspective building to develop a shared understanding of the key concepts of decentralized governance and leadership;

- knowledge building to understand the roles, responsibilities, powers and functions of political leadership;

- skill building to plan, and communicate with different interest groups, interfacing and mobilization skills;

- agency building to participate in and articulate their concerns and priorities.

\section{Content}

- Issues of governance, democratic decentralized governance including salient features of 73rd amendment; provisions related to panchayat meetings, ward meetings in state-specific acts, provisions related to gram sabha, panchayat budget and finance, social justice and economic empowerment in statespecific acts; committees in panchayats.

- Processes in gram sabha and panchayat such as quorum/agenda decisions, resolution and proceeding writing, convening ward/gram sabha meeting; conducting panchayat meetings and standing committee meetings, bottomup decentralized planning (micro planning/ward-level planning) and preparing panchayat budget.

- Roles and responsibility in the exercise of power to participate and articulate effectively their concerns and priorities in the meetings of gram sabha and panchayats. 


\section{Training methodology}

The facilitators were well rooted in the issues relating to SC leadership. By using participatory learning methods, they facilitated the learner group to understand their roles as people's representatives. Training methodology was a mix of participatory learning and action methods such as:

- large group and small group discussion and sharing of experiences;

- lectures;

- role plays.

\section{Prem Chadha Memorial Youth Leadership Programme}

The youth have abundant potential to develop a democratic and prosperous world. Yet youth today feel deprived of a sense of belonging to society. This is a symptom of under-engagement. A sense of exclusion often forces young people into a state of marginality where they become mere bystanders in the world of work and decision making. Their participation can gain momentum and revitalize the society when their potential is harnessed through meaningful education and training (Foster and Naidoo, 2001).

\section{The programme}

The Prem Chadha Memorial Youth Leadership Programme was initiated by PRIA in memory of the late Mr Prem Chadha, a founder of PRIA. He was the Chair of PRIA's Governing Board for ten years. The first camp of the Prem Chadha Memorial Youth Leadership Programme was conducted in Gram Vikas campus (Berhampur), Orissa, in December 2009. A total of 82 students - 35 girls and 47 boys, from Jharkhand (25), Chattisgarh (24) and Orissa (33) participated in this first five-day residential training programme.

Education and training for youth leadership had multipronged objectives as below.

\section{General}

- to enable youth from marginalized regions, communities and social groups to acquire, enhance and nurture their leadership capabilities;

- to nurture and strengthen the capacities and skills of participants to help them to emerge as self-confident and proficient individuals who can take life in their stride.

\section{Specific}

- building perspectives on self-identity and collectivity;

- building competencies such as computer literacy, personal grooming, communication for confidence building;

- building knowledge on reproductive and sexual health, information and communication technologies, career options. 


\section{Content}

- Perspective building on self-identity and collectivity: self-awareness and empathy, understanding self - as a social construct and using this understanding to empower oneself. It helps to identify strengths and understand better how to deal with the various inequalities and challenges they encounter. And team building and leadership - learners learn to deal with not just their own power but also with the power they have in large numbers.

- Skill building on life skills, effective communication and interpersonal skills, creative and critical thinking skills, personal grooming, computer fundamentals (Microsoft Windows, Microsoft Word, Microsoft Excel, World Wide Web).

- Knowledge building on adolescent reproductive and sexual health; information and communication technology - computers, radio, mobiles, TV and cellular technology; and career options.

\section{Training methodology}

Resource persons from different organizations like Patang, Odisha Voluntary Health Association (OVHA), Inter Finite Technologies and Time extended their expertise in conducting various sessions. By skilfully using participatory learning methods they facilitated the learner group to understand their potentials. Training methodology was a mix of participatory learning and action methods such as:

- lectures;

- activities;

- games;

- group discussions;

- role-play;

- films;

- practice sessions. 